\title{
Modeling and Effects of Base Drag on Thick Airfoils Design
}

\author{
F. Grasso ${ }^{1}$ \\ Energy research Centre of the Netherlands (ECN), Petten, the Netherlands, 1755LE.
}

\begin{abstract}
The selection of the proper airfoils plays a crucial role in the design of wind turbine rotors to maximize the performance and reduce the cost of energy. As the size of the wind turbines is increasing, the performance of the airfoils at the root are very important, not only for structural reasons but also for aerodynamics. Flat back geometries are very attractive in order to achieve both structural and aerodynamic performance; however, they represent a challenge from the computational point of view because of the unsteady vorticity shedded at the trailing edge. The present work is focused on the development of such geometries. In particular, the first part of the work is dedicated to the modeling of the base drag in order to improve the accuracy of the numerical predictions for this class of airfoils. In the second part instead, the effects due to the base drag contribution during the design of new airfoils are investigated. Numerical optimization is used for this task. The results are discussed and compared to previous results and existing airfoils.
\end{abstract}

\section{Nomenclature}

$\begin{array}{ll}\alpha & =\text { angle of attack } \\ c & =\text { airfoil chord } \\ \mathrm{Cd} & =\text { drag coefficient } \\ \mathrm{Cd}_{\text {base }} & =\text { base drag coeffcient } \\ \mathrm{Cl} & =\text { lift coefficient } \\ \mathrm{Cl}_{\max } & =\text { maximum lift coefficient } \\ \mathrm{Cm}_{\mathrm{c} / 4} & =\text { moment coefficient referred to the quarter point of the chord } \\ \mathrm{h} & =\text { non dimensional trailing edge thickness } \\ \mathrm{L} / \mathrm{D} & =\text { aerodynamic efficiency } \\ \mathrm{t} & =\text { non dimensional airfoil thickness }\end{array}$

\section{Introduction}

$\mathrm{D}$ ESIGN of airfoils specifically suited for wind turbine blade applications is important in the continuing development of wind turbines. Because of the intrinsic requirements in terms of design point, off-design capabilities and structural properties, new airfoils dedicated to wind turbine application have been developed ${ }^{1-4}$. However, most of these airfoils were designed for the outer part of the blade where the aerodynamic requirements have higher priority compared to the structural ones. Nowadays, the design of geometries with relatively large trailing edge thickness (blunt trailing edge or flat-back airfoils) became popular ${ }^{4-7}$ in order to improve the airfoil's lift performance. From numerical point of view, this class of geometries is challenging, due to their intrinsic characteristics and the lack of experimental data to validate the numerical predictions. Most of the numerical investigations performed on flat back airfoils are done by using high order CFD (i.e. LES). This is due to the important role played by the unsteady wake as consequence of alternate vortices generated at the trailing edge. In order to evaluate stall and drag performance, these phenomena are not negligible. On the other hand, CFD tools are not well suited for design purpose because they are computational and time expensive.

In previous works by the present author, the panel code $\mathrm{RFOIL}^{8}$ was used to design new airfoils, due to the generally high accuracy of the prediction both in terms of lift and drag. However, when the trailing edge thickness becomes large, the numerical accuracy drops, leading to sensible under prediction of the drag. In the next section a validation of RFOIL for thick geometries is illustrated; based on the results, a correction equation for the base drag

\footnotetext{
${ }^{1}$ Aerodynamicist Scientist, Wind Energy Technology, Westerduinweg 3; grasso@ecn.nl, AIAA Associate Fellow.
} 
is developed and discussed. Finally, the effects of the base drag are investigated in terms of airfoil shape and its performance.

\section{RFOIL Validation for Thick Airfoils}

RFOIL is a modified version of XFOIL ${ }^{9}$ featuring an improved prediction around the maximum lift coefficient and capabilities of predicting the effect of rotation on airfoil characteristics. Figures 1 and 2 show the validation of RFOIL considering the NACA63 3418 airfoil ${ }^{10}$ as reference for the comparisons.

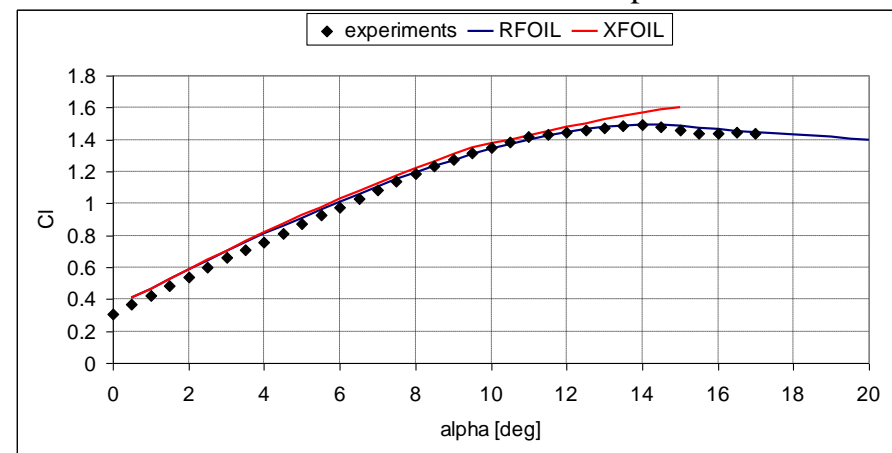

Figure 1. RFOIL validation; lift curve. NACA63,418 airfoil. 6 millions Reynolds number, free transition. Experimental data from Ref. 10.

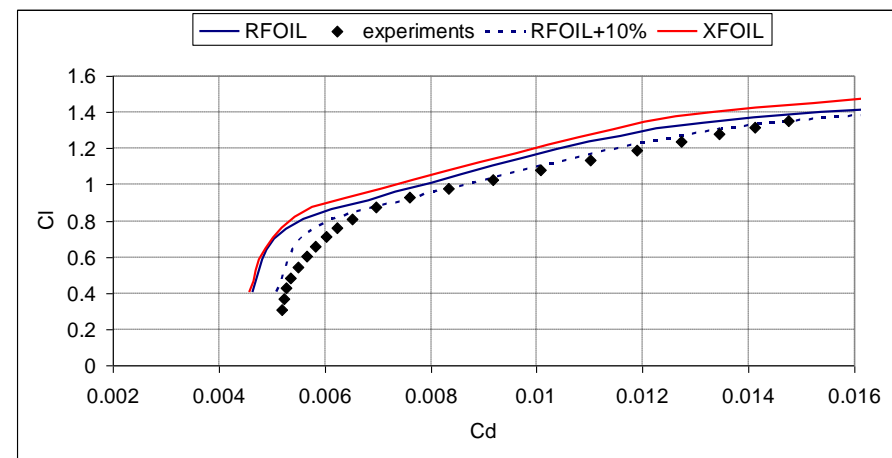

Figure 2. RFOIL validation; drag polar. NACA633418 airfoil. 6 millions Reynolds number, free transition. Experimental data from Ref. 10.

While XFOIL is predicting accurately only the linear part of the lift curve and the beginning of the separation part, RFOIL gives very good results also in stall and post stall conditions. Regarding the drag, both codes under predict the real values, but RFOIL matches the experimental data if a $10 \%$ penalty is added. The same accuracy has been found for a large variety of geometries and different Reynolds numbers.

Due to the unique features of thick airfoils, (i.e. blunt trailing edge), a specific assessment of RFOIL accuracy has been performed for this class of geometries. For this purpose, DU00-W2-350, DU-00-W2-401, FX77-W-343, and FX77-W-400 airfoils have been used as reference to validate the numerical predictions. The Delft University (DU) airfoils have been tested at Delft University, while the FX geometries at Stuttgart University. All the tests have been performed at 3 millions Reynolds number in free transition, except for the FX77-W-400 where the Reynolds number was 4 millions. 

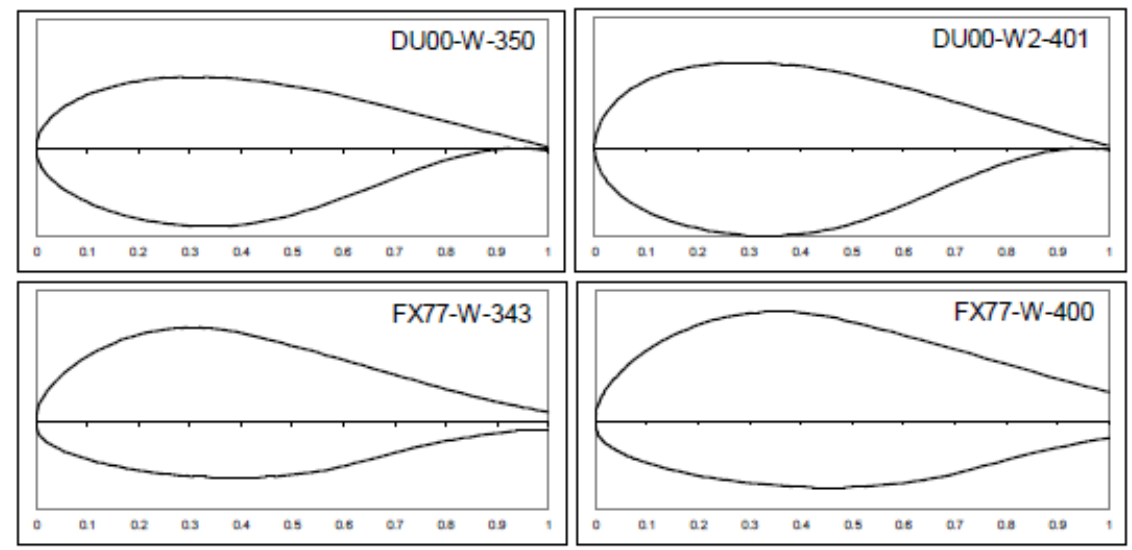

Figure 3. Airfoils selected for the validation.

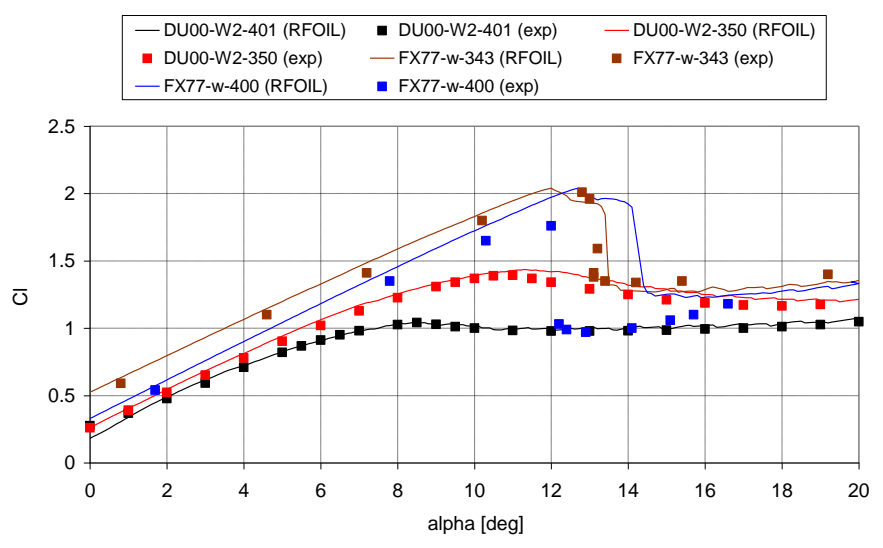

Figure 4. Validation for thick airfoils; lift curve. Reynolds number: 3 million. Experimental data from Refs. 4 and 11.

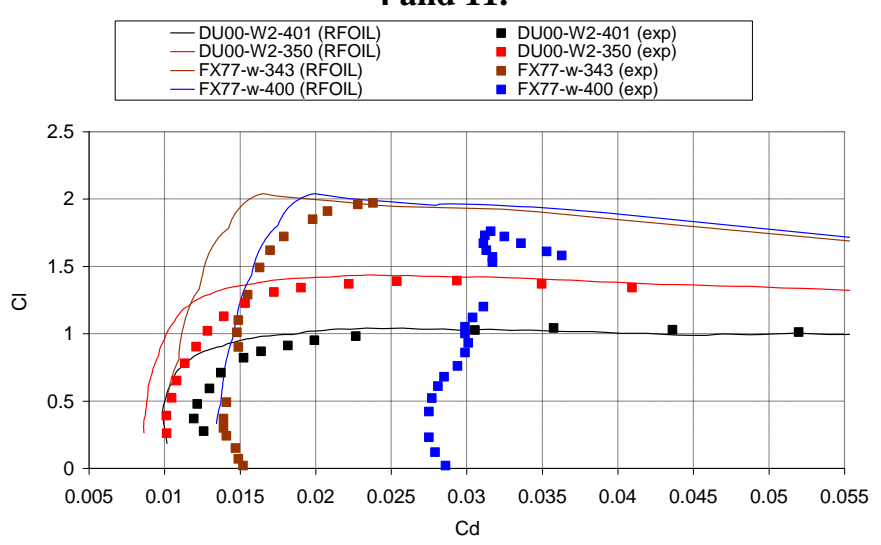

Figure 5. Validation for thick airfoils; drag polar. Reynolds number: 3 million. Experimental data from Refs. 4 and 11.

Looking at the lift curves (Fig.4), the agreement is very good for the DU geometries: the numerical predictions are on top of the experiments also in post stall condition. In terms of drag (Fig. 5), an underestimation around $13 \%$ has been found, which is in line with the results of previous validations done on thinner airfoils. With regards to the FX airfoils, the general accuracy is lower. The shape of the lift curves is quite well taken, but for the FX77-W-400 there is an overestimation of the maximum lift coefficient and the angle of stall. The abrupt shape of the stall is anyway captured. In terms of drag instead, the underestimation is larger, especially for the $40 \%$ airfoil. 
Considering the selected geometries, the lack in accuracy seems to be due not to the airfoil thickness itself but to the trailing edge thickness; for large values of trailing edge thickness, especially the drag is not well predicted.

This conclusion should not be surprising since the mathematical formulation of the panel codes are in general not suited for such cases. Including the base drag contribution could lead to an improvement in RFOIL capabilities; from the design point of view, have better accuracy during the simulations would lead to more reliable results and more realistic geometries.

\section{Base Drag Modeling}

An engineering approach has been used to obtain a correction for the base drag. The formula proposed by Hoerner ${ }^{5}$ has been considered as starting point (see eq.(1)). In this formulation, the base drag is a function of the drag coefficient $\left(\mathrm{C}_{\mathrm{d}}\right)$ and the non dimensional trailing edge thickness $(\mathrm{h})$.

$$
\Delta \mathrm{C}_{\mathrm{dbase}}=0.135^{*} \mathrm{~h}^{4 / 3} / \mathrm{C}_{\mathrm{d}}{ }^{1 / 3}
$$

In order to evaluate the effects of this formula, the base drag contribution has been added to the drag polar curves discussed in the previous paragraph (Fig. 5). Figure 6 shows the results. Comparing with Fig. 5, it can be observed that there is a hardly visible change in the data regarding the DU airfoils. This trend is consistent with the expectations and the eq.(1). In facts, the base drag contribution for the DU airfoils is small due to the small values of trailing edge thickness. For the FX geometries instead, the contribution due to the base drag improves the accuracy of the predictions. However, comparing the data concerning the FX-W-343 and FX-W-400, it can be seen that the percentage amount of under prediction is not equal. This suggests that the formula proposed by Hoerner, should be improved.

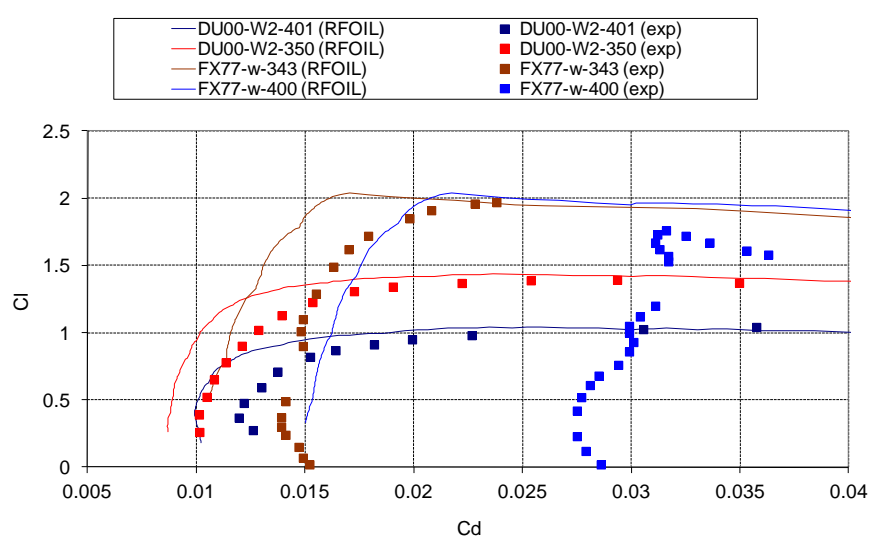

Figure 6. Effects of the base drag correction; drag polar curves including the base drag term proposed by Hoerner. Reynolds number: 3 millions (4 millions for FX77-W-400). Experimental data from Refs. 4 and

11.

In the present work, the equation proposed by Hoerner has been used as starting point for a new correction formula. Looking at the equation, the geometrical parameters are not directly connected to the aerodynamic ones. Although this structure has been kept, some changes in the terms have been done.

From the above mentioned considerations, the geometrical term could be more complex; in particular, the airfoil thickness has been added in the equation. In this way not only the trailing edge thickness but the product with the airfoil thickness is in the equation.

All the terms in eq.(1) affect the predictions by adding an offset contribution. The geometrical term plays a major role; however, also the exponent of the term related to the drag coefficient has been slightly altered. Changing the exponent on the $\mathrm{C}_{\mathrm{d}}$ term, it also slightly modifies the slope of the drag curve and it partially counter balances the changes in the geometrical term. After the modifications, the exponent of $\mathrm{C}_{\mathrm{d}}$ is not one third but one fourth

Figure 7 shows the results of RFOIL validation (see Fig. 5) after the modified equation of the base drag contribution has been included. For the DU airfoils the results do not differ significantly from the original values or from the results with Hoerner's formula because the trailing edge thickness is quite small. Instead for the FX 
geometries, the modification of eq.(1) has positive effects since the mismatch between numerical predictions and experimental data is reduced. While the original predictions showed a different level of under prediction, the corrected results are in line with the 10\% - $13 \%$ inaccuracy generally found during the design and analysis of conventional geometries.

It should be noticed however, that the shape of the drag polar curves obtained numerically are not changed because of the base drag contribution. This is expected because the base drag adds an offset to the original values and is evident comparing experiments and RFOIL predictions for the FX77-W-400 airfoil. In order to change the actual shape of the drag curves, a more detailed investigation on the transition model implemented in RFOIL should be performed.

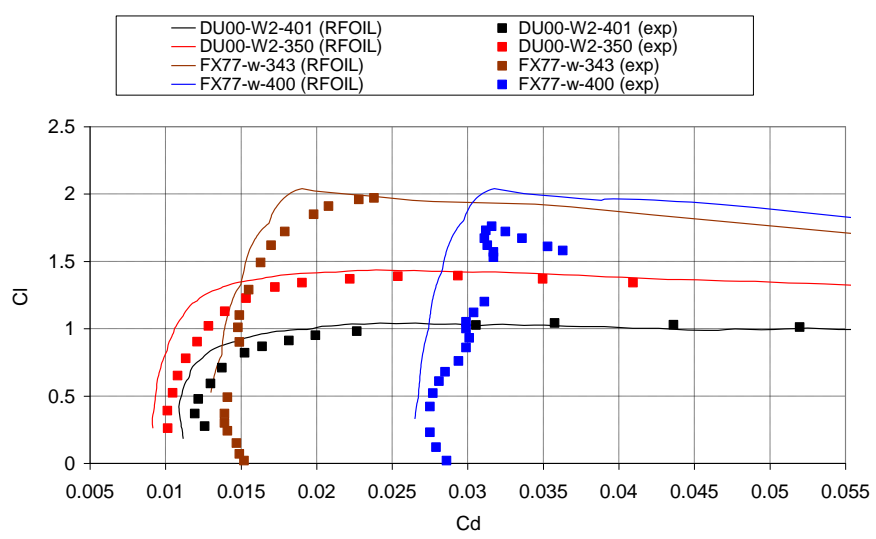

Figure 7. Effects of the modified base drag correction. Reynolds number: 3 millions (4 millions for FX77W-400). Experimental data from Refs. 4 and 11.

\section{Effects of the Base Drag on Airfoil Design}

Once an improved expression for the base drag has been derived, the investigation has been focused on understanding what is the role of this extra term during the design of new thick airfoils. It is also important to predict the effects due to the base drag on the actual geometry.

To do this, the design of a new thick airfoil of minimum 35\% c thickness has been performed, by using numerical optimization. In particular, an advanced gradient based algorithm ${ }^{12}$ has been implemented in combination with RFOIL code. For this class of geometries, beside the aerodynamic performance, also structural requirements should be taken into account. However, in order to focus on the effects of the base drag without side effects due to other constraints, the objective function consists in maximizing the aerodynamic efficiency (L/D) of the airfoil at 6 degrees of angle of attack, at 3 millions Reynolds number. In terms of constraints, beside the minimum thickness of $35 \%$, a minimum trailing edge thickness of $5 \%$ of the chord has been prescribed. The design has been done with imposed transition (1\% of the chord on the suction side and $10 \%$ on the pressure side); this is to obtain realistic solutions, robust in regards of roughness and with good performance also in off design conditions. A more complete description of the design procedure can be found in Ref. 13.

The geometry is parameterized by using a Bezier-based description developed by the present author ${ }^{13}$, where the airfoil is divided in four pieces (each of them is described by a cubic curve) for a total of 13 control points (26 degrees of freedom). In the present work, 15 degrees of freedom have been used, as summarized in table 1 .

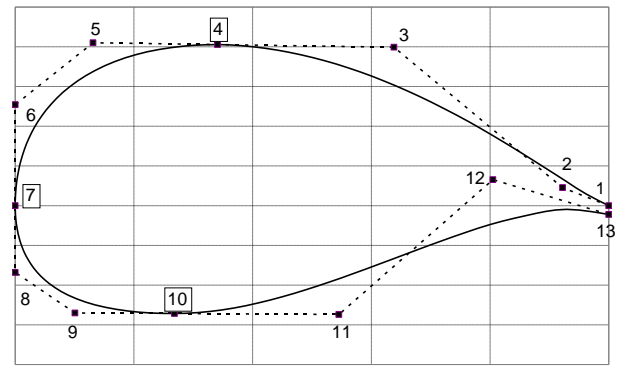

Figure 8. Sketch of the geometrical parameterization. 
Table 1. Scheme of the design variables and boundaries used during the optimization. *h and $\mathbf{v}$ indicate a horizontal or vertical variable.

\begin{tabular}{cccc}
\hline \hline ID & $\begin{array}{c}\text { Control } \\
\text { point* }\end{array}$ & $\begin{array}{c}\text { Lower } \\
\text { bound }\end{array}$ & $\begin{array}{c}\text { Upper } \\
\text { bound }\end{array}$ \\
\hline 1 & $2 \mathrm{~h}$ & 0.7 & 0.8 \\
2 & $3 \mathrm{~h}$ & 0.4 & 0.5 \\
3 & $5 \mathrm{~h}$ & 0.09 & 0.15 \\
4 & $9 \mathrm{~h}$ & 0.09 & 0.15 \\
5 & $11 \mathrm{~h}$ & 0.4 & 0.5 \\
6 & $12 \mathrm{~h}$ & 0.7 & 0.8 \\
7 & $1 \mathrm{v}$ & 0 & 0.1 \\
8 & $2 \mathrm{v}$ & 0.03 & 0.2 \\
9 & $3 \mathrm{v}$ & 0.08 & 0.25 \\
10 & $5 \mathrm{v}$ & 0.08 & 0.25 \\
11 & $6 \mathrm{v}$ & 0.03 & 0.1 \\
12 & $8 \mathrm{v}$ & -0.1 & -0.02 \\
13 & $9 \mathrm{v}$ & -0.25 & -0.02 \\
14 & $11 \mathrm{v}$ & -0.25 & 0.04 \\
15 & $12 \mathrm{v}$ & -0.1 & 0.09 \\
\hline \hline
\end{tabular}

The control points are named according to fig. 9. The thickness of the airfoil can change between $10 \%$ and $50 \%$ of the chord. Also, the trailing edge thickness can increase up to $20 \%$ of the chord.

The design has been performed twice. During the first design, the base drag has not been included during the design, but added only after the optimal shape was obtained to estimate the base drag. In the second case, the base drag term was included already during the design iterations. The results of the optimizations have been compared and they are shown in Figs. 9-12.

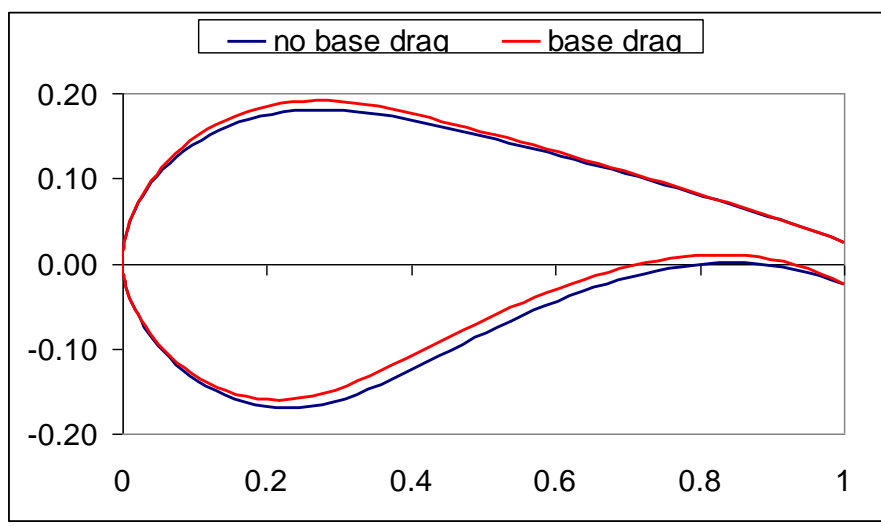

Figure 9. Effect of the base drag; comparison between the geometries. 


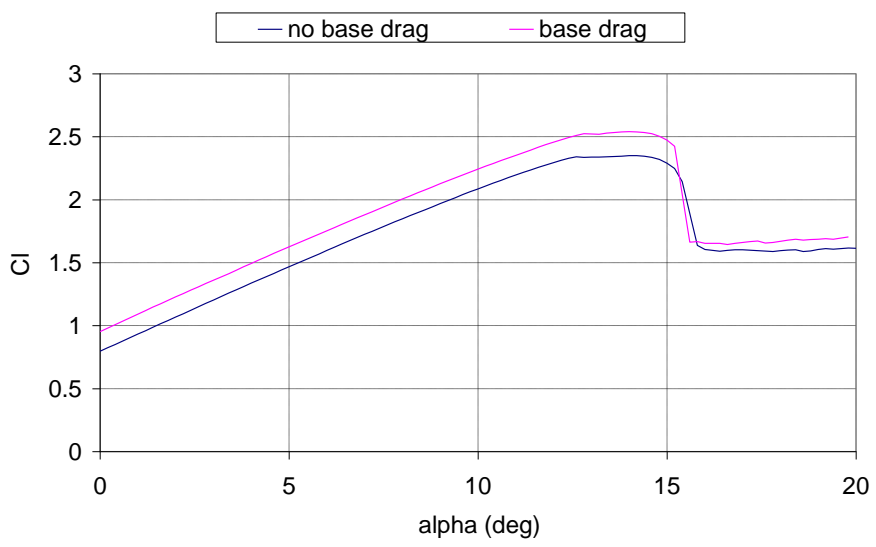

Figure 10. Effect of the base drag; comparison between the lift curves. RFOIL prediction, free transition, 3 millions Reynolds number.

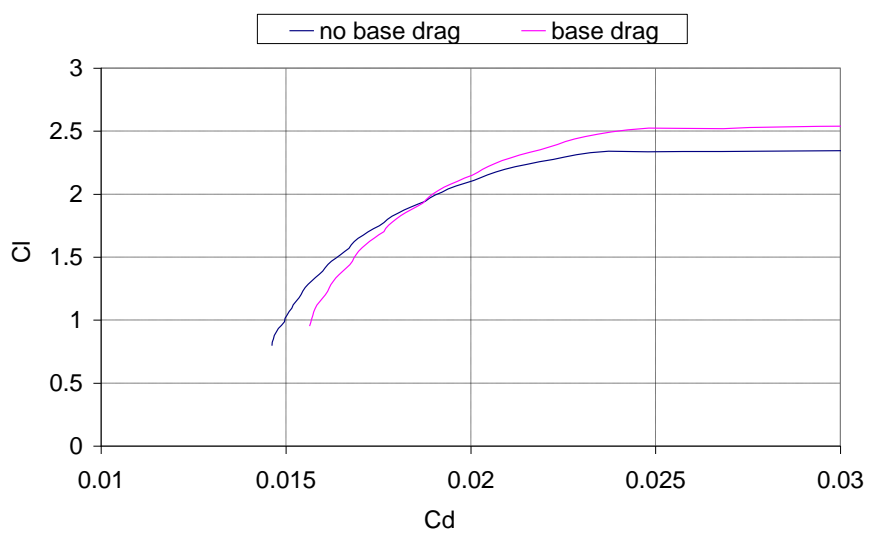

Figure 11. Effect of the base drag; comparison between the drag curves. RFOIL prediction, free transition, 3 millions Reynolds number.

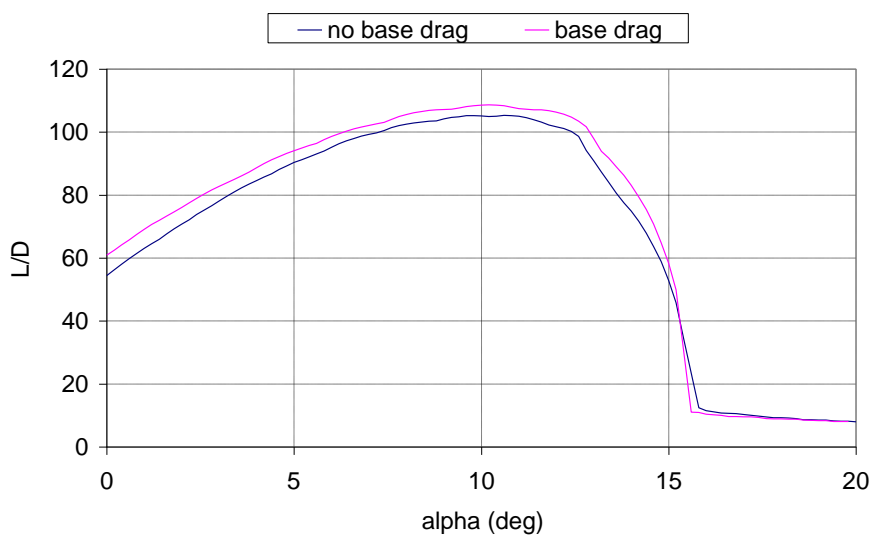

Figure 12. Effect of the base drag; comparison between the efficiency curves. RFOIL prediction, free transition, 3 millions Reynolds number.

Both geometries have the same thickness, but the shape of most of the pressure side and the suction side around the $30 \%$ of the chord are different. From the optimization point of view, the presence of the base drag is a penalty term that forces the algorithm to generate a solution able to counter balance this penalty. In particular, the solution that incorporates the base drag during the design is more cambered, so there is more lift (Fig. 10). As 
consequence, the aerodynamic efficiency produced by the airfoil incorporating the base drag is anyway larger than for the other shape.

Due to the geometrical constraint on the airfoil thickness, there is also a small difference on the suction side to satisfy the constraint. Globally speaking, these geometrical differences do not lead to significant changes on the shape of the lift curve and efficiency curve. Only at the stall, there is tendency for a sharper stall that is caused by the difference in shapes at the suction side. The small increment in thickness on the suction side, combined with the fact that the recompression in the rear part of the airfoil is faster than for the other geometry, is expected to produce faster separation. For the drag (Fig.11), one airfoil has larger drag for low values of angle of attack, but better performance for high assets.

Analyzing the geometries in fixed transition (1\% of the chord on the suction side, $10 \%$ on the pressure side), the effects are more evident but still consistent with what already discussed. In practice, if a smooth stall is required, specific constraints need to be prescribed during the design.

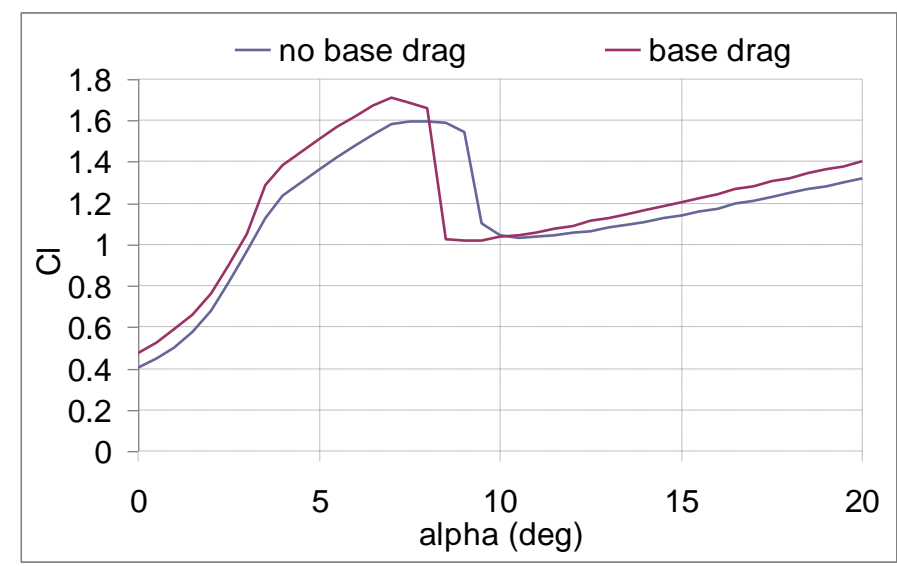

Figure 13. Effect of the base drag; comparison between the lift curves. RFOIL prediction, fixed transition, 3 millions Reynolds number.

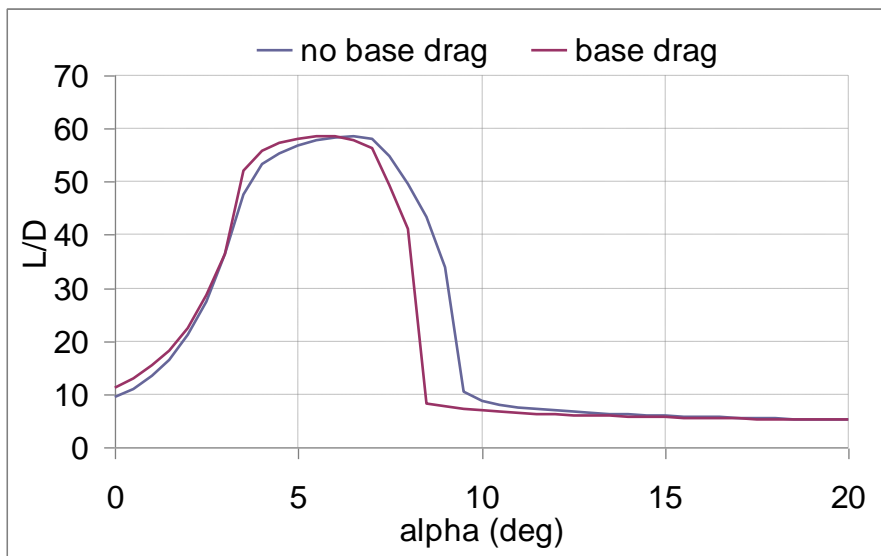

Figure 14. Effect of the base drag; comparison between the efficiency curves. RFOIL prediction, fixed transition, 3 millions Reynolds number.

\section{Conclusions}

Thick airfoils play an important role for the development of large wind turbines and flat back geometries are able to improve aerodynamic and structural performance. In order to design this class of airfoils, an accurate tool is needed that is also not expensive in terms of computational costs. 
In the present work, a correction formula to describe the base drag has been derived based on experimental data. The preliminary results are consistent; however, the limited amount of experimental data available in literature can affect the robustness of this formulation.

Looking at the effects of including the base drag during the design, this affects the design itself because to obtain thick airfoils with high efficiency, the lift generated should compensate the additional drag. A case study focused on the design of thick airfoil has been performed by including the additional drag during the design procedure. The results are in line with the expectations and the performance are higher when the base drag is accounted during the design process.

\section{Acknowledgments}

The present work has been carried out partially under the FP7 European Project INNWIND.EU (FP7 project no. 308974).

\section{References}

1. Tangler, J.L., Somers, D.M., “NREL Airfoil Families for HAWT’s”. Proc. WINDPOWER'95, Washington D.C., 1995; pp. 117-123.

2. Björk, A., "Coordinates and Calculations for the FFA-W1-xxx, FFA-W2-xxx and FFA-W3-.xxx Series of Airfoils for Horizontal Axis Wind Turbines". FFA TN 1990-15, Stockholm, Sweden 1990.

3. Fuglsang, P., Bak, C., "Design and Verification of the new Risø-A1 Airfoil Family for Wind Turbines". AIAA-20010028

4. Timmer, W.,A., van Rooij, R.P.J.O.M., "Summary of the Delft University Wind Turbine Dedicated Airfoils". AIAA2003- 0352.

5. Hoerner, S.,F., “ Base Drag and Thick Trailing Edge”, Journal of the Aeronautical Sciences, Vol. 17, No. 10, Oct. 1950, pp. 622-628.

6. Hoerner, S. F., and Borst, H. V., Fluid-Dynamic Lift, Hoerner Fluid Dynamics, Bricktown, NJ, 1985, pp. 2-10, 2-11.

7. van Dam, C.P., Mayda, E.A., and Chao, D.D., "Computational Design and Analysis of Flatback Airfoil Wind Tunnel Experiments", SAND2008-1782, Sandia National Laboratories, Albuquerque, NM, March 2008.

8. van Rooij, R.P.J.O.M., "Modification of the boundary layer calculation in RFOIL for improved airfoil stall prediction",Report IW-96087R TU-Delft, the Netherlands, September 1996.

9. Drela, M., "XFOIL 6.94 User Guide", MIT Aero \& Astro, Dec 2001.

10. Abbott, I., Von Doenhoff, A., Theory of Wing Sections, Dover Publications, Inc., Dover edition, 1958.

11. Althaus, D., "Stuttgarter Profilkatalog II: Niedriggeschwindigkeitsprofile", Vieweg\&Sohn Braunschweig, Stuttgart, 1996.

12. Schittkowski, K., "NLPQLP: A new Fortran implementation of a sequential quadratic programming algorithm - user's guide, version 1.6", Report, Department of Mathematics, University of Bayreuth, 2001.

13. Grasso, F., "Usage of Numerical Optimization in Wind Turbine Airfoil Design", 28th AIAA Applied Aerodynamics Conference, AIAA, Chicago, IL, 28 June-1 July, 2010. AIAA2010-4404. Also, AIAA, Journal of Aircraft, Vol.48, No.1, Jan.- Feb. 2011, DOI: 10.2514/1.C031089.

14. Grasso, F., "Multi-Objective Numerical Optimization Applied to Aircraft Design", Ph.D. Thesis, Dip. Ingegneria Aerospaziale, Università di Napoli Federico II, Napoli, Italy, December 2008.

15. van Rooij, R.P.J.O.M., Timmer, W.A., "Rougness Sensitivity Considerations for Thick Rotor Blade Airfoils", AIAA, AIAA 2003-0350, 2003. 